\title{
LA REPRESENTACIÓN DE LA VIOLENCIA EN LA PARALITERATURA HONDUREÑA DE INICIOS DEL SIGLO XXI
}

\author{
Fernando Escobar ${ }^{1}$ \\ CEUTEC, Tegucigalpa, Honduras. \\ (Enviado: Octubre, 2017/Aceptado: Agosto, 2018)
}

\begin{abstract}
Resumen
En las primeras décadas del siglo XXI, Honduras fue nombrado uno de los países más violentos de América Latina. El fenómeno de la violencia adquirió distintos matices y problemáticas: desde el fenómeno pandilleril (maras), pasando por el narcotráfico, la violencia estatal, feminicidios, etc. Las manifestaciones culturales han hecho esfuerzos importantes para dar sentido o significación a un escenario complejo y cambiante. Obras que se han asociado a la cultura popular (la cultura baja), como la paraliteratura, han podido generar productos culturales con un impacto social. Es decir, obras de consumo popular, escritas en medios masivos (diarios, blogs, historietas) pueden haber contribuido de una forma más contundente a la construcción de la representación de la violencia en el país. Autores que cultivan el género policiaco como Mario Berríos o Carmilla Wyler, cuya finalidad es eminentemente comercial, contribuyen activamente al discernimiento del significado de la violencia en el país. Por otro lado, las novelas gráficas o ‘comics’ también han servido como nuevos vehículos de comunicación, como en el caso de Germán Andino, en su novela gráfica "Transformar números en barcos piratas”.
\end{abstract}

Palabras Claves: Violencia, Representación, Literatura, Paraliteratura, Honduras.

\begin{abstract}
In the first decades of the $21^{\text {st }}$ century, Honduras has been named one of the most violent countries in Latin America. The phenomenon of violence has acquired different shades and relationships: from the gang phenomenon (maras), passing through drug trade, state violence, gender violence, etc. Cultural manifestations have made strong efforts to give sense and meaning to a complex and changing landscape. Projects that have been associated to popular culture (lower culture), such as paraliterature, have been able to create cultural products of great social impact. That is, works for popular consumption, written in mass media (newspapers, blogs, comics) have contributed in a convincing way to the construction of the representation of violence in the country. Authors that use the police novel genre like Mario Berrios or Carmilla Wyler, whose work is eminently commercial, contribute actively to attribute meaning to the violence in the country. On the other hand, graphic novels of 'comics' have also served as new communications vehicles, such is the case of Germán Andino, in this graphic novel "Transformar números en barcos piratas".

Keywords: Violence, Representation, Literature, Paraliterature, Honduras.
\end{abstract}

\footnotetext{
${ }^{1}$ Autor para correspondencia. Email: fernando.escobar@unitec.edu.hn
} 


\section{Introducción}

El nivel de violencia en Centroamérica medido en homidicidios es diez veces mayor al promedio mundial, y esta evaluación no se refiere a la visión occidental de esta región como un lugar de guerras civiles, revoluciones o dictaduras militares, por el contrario, representa una situación después de la "tercera ola de democratización" enmarcada dentro de un periodo de paz (Zinecker, 2017). Para el occidente, América Latina siempre ha sido un foco de violencia (Mackenbach \& Maihold, 2015), y esta visión ha fortalecido el vínculo entre violencia, barbarie y el mundo subdesarrollado. Esta categorización sobre la violencia afecta de modo especial a Centroamérica y de forma particular a Honduras. No solo podemos hablar de una historia de la violencia en Honduras, sino que podemos identificar la transformación de las fuerzas y formas que han caracterizado la violencia en los últimos 50 años.

El siguiente trabajo tratará de identificar la forma en que ciertas manifiestaciones culturales han representado la violencia de los últimos 20 años. El significado que la cultura ha tenido en la incorporación de la violencia en la identidad Latinoamericana, ya se mencionaba en 1970, con la publicación de Imaginación y violencia en América de (Dorfman,1970):

"La violencia ha sido siempre importante en nuestra literatura, tal como lo ha sido en nuestra historia; pero hasta el naturalismo, las manifestaciones de este problema, aunque sintomáticas y frecuentes, no fueron el resultado de su predominio en una determinada sensibilidad generacional. La muerte se vivía en América desde tópicos literarios europeos. Sin embargo, a partir del naturalismo el problema de la violencia pasa a ser el eje de nuestra narrativa, ya que al descubrir la esencia social de América, las luchas y sufrimientos de sus habitantes, la explotación que sufrían a manos de la oligarquía y del imperialismo, la forma en que la tierra los devoraba, se descubrió, paralelamente, que nuestra realidad era violenta, esencialmente violenta.”

Dorfman habla desde la perspectiva literaria: los modelos que se habían utilizado eran eminentemente europeos. El triunfo de la literatura latinoamericana estribó de la capacidad de los autores latinoamericanos en crear nuevos modelos para representar su realidad.

Estos modelos literarios han podido representar desde la violencia de la colonización (Araucana de Ercilla), pasando por la explotación del indígena (El mundo es ancho y ajeno de Ciro Alegría), el enclave bananero (Prisión verde de Ramón Amaya Amador), hasta la lucha revolucionaria de años 70 (Fuego en la montaña de Omar Cabezas), por mencionar algunos casos. El autor latinoamericano busca atribuir significado y propósito a la violencia que padecía los pueblos.

La última ola de violencia que vivimos, que entre otros factores se caracteriza por nuevos actores y condiciones como el narcotráfico internacional y la globalización, parece no haber encontrado las formas estético-literarias para su representación (Michael, 2015). Joachim Michael (2015) habla del caso mexicano, sin embargo, podemos extrapolar esta apreciación para el resto de América Latina:

Ya en 2005, el crítico Rafael Lemus somete la narconovela a una crítica mordaz. Lemus admite que se trata de un nuevo "subgénero" dada la cantidad de autores que publican novelas sobre el narcotráfico. Pero el crítico ve que la narconovela fracasa, tal como se presenta hasta el momento: "Una narrativa sobre el narco, una estrategia ordinaria: costumbrismo minucioso, lenguaje coloquial, tramas populistas.” O sea, el desafío de la 
pesadilla descomunal del narcotráfico, la narconovela responde con recetas comunes (realismo, melodrama, novela negra, etc.).

En Honduras esto se ve reflejado en varias obras, como la ganadora del Premio Centroamericano y del Caribe de Novela "Roberto Castillo", del hondureño Geovanni Rodríguez: "Los días y los muertos" (2017). Aunque que es una obra de reconocida calidad literaria y de aceptación en los círculos académicos, aún recurre a modelos de literarios tradicionales, en este caso la novela policial.

El investigador Maihold (2015) en “La comunicación de la violencia: narcorridos, narcomantas y narcosantos", encuentra nuevas manifestaciones culturales asociadas con el fenómeno de la violencia generada por el narcotráfico, tomando como ejemplo los narcocorridos y otros fenómenos culturales asociados al narcotráfico en México. El presente estudio estructura la representación de la violencia en manifestaciones culturales no tradicionales en Honduras: puntualmente en la paraliteratura.

\subsection{Objetivo general}

- Analizar la representación de la violencia en tres obras de la paraliteratura hondureña de inicio del siglo XXI.

\subsection{Objetivos específicos}

- Conceptualizar la paraliteratura como un género literario propio de la cultura de masas y principal vehículo de divulgación del fenómeno de la violencia en Honduras.

- Identificar los ejes comunicativos que caracterizan estas obras y su abordaje de la violencia.

- Describir como la representación de la violencia de cada obra analizada contribuye a la construcción de una consciencia de la violencia y nuestra respuesta ante ella.

\section{Marco teórico}

\subsection{Paraliteratura}

Entendemos como paraliteratura a una colección de trabajos escritos relegados a los márgenes de literatura reconocida y frecuentemente descartada como "subliteratura" a pesar de sus similitudes con formas reconocidas del canon literario. La paraliteratura incluye muchas formas de teatro y ficción popular: literatura para niños, novelas policiales, ciencia ficción y fantasía. Generalmente, asociamos la paraliteratura con productos culturales diseñados para el consumo masivo o popular. Críticos literarios como Jaques Derrida y Roland Barthes han manifestado su desdén por este concepto, ya que en realidad no aporta ningún tipo de reflexión estéticaliteraria. Es decir, dentro de un género literario pueden existir obras de gran calidad estética, independientemente sus fines o éxito comercial.

Sin embargo, el enfoque de este estudio no es literario, sino cultural. Las obras que se analizarán, serán evaluadas por sus valores culturales, su relación contextual y su impacto social. Utilizamos el concepto de paraliteratura para resaltar el carácter marginal de estas obras dentro del contexto académico. Se han realizado números estudios sobre la literatura centroamericana y su representación de la violencia, sin embargo, hay otras obras con gran impacto social y cultural que permanecen fuera de la crítica literaria, y discusión académica. 
Como lo menciona Michael (2015), es prioritario incluir a estas obras dentro de la discusión sobre la violencia, especialmente aquellas manifestaciones con amplia difusión.

\subsection{La transformación de la violencia}

La elección de estas formas literarias responde a una necesidad de nuevas formas de violencia en la región. La región pasó de una violencia centrada en un conflicto político de opresión y desigualdad, alentado por la Guerría Fría, durante las décadas de los 70 y 80 . Los años 90 fueron un periodo de transición en donde "la creciente difusión y privatización de la violencia que parte de los rebeldes, del crimen organizado o cotidiano, pone de relieve un fenómeno que describe una parte central del poceso de transformación de la violencia” (Mackenbach \& Maihold, 2015).

El monopolio del poder por parte del Estado es desafiado por el crimen organizado; la violencia social abarca a más elementos de la sociedad. Las formas de violencia y sus secuelas con la sociedad se modifican sustancialmente frente a los setenta y ochenta, caracterizadas por la guerrilla y la violencia de cuño político. Actualmente parace que la encrucijada no radica en la violencia estatal o contraestatal, por el contrario, en la violencia no estatal que compensa, complementa, socava o ignora al Estado (Mackenbach \& Maihold, 2015).

La proliferación de formas más complejas de violencia se ha convertido en una parte inescapable de la vida cotidiana latinoamericana. Es una realidad con múltiples ramificaciones para la población, generando un escenario sociopolítico decisivo y de repercusiones a largo plazo.

Los estudios sobre el tema de cultura y violencia siguen dos paradigmas generales: a) algunos perciben la violencia como un fenómeno patológico que disrumpe un orden social establecido, y b) otros la entienden como un problema estructural que forma un orden social, a niveles individuales y colectivos (Dueñas \& Rueda, 2011). Con un interés tanto en los niveles simbólicos y físicos de la violencia, las obras se analizan examinando los sistemas de valores, formas de representación y las estructuras significacionales que subyacen dentro de cada forma de violencia.

Un enfoque interdisciplinario va más allá de la caracterización de la violencia estructural y la discusión sobre su legitimidad (o falta de ella) para estudiar la violencia dentro de la lógica de su práctica. Entender la violencia desde esta perspectiva implica no solo examinar sus manifestaciones explícitas y sus efectos, sino también los actos sociales que la preceden, provocan y nombran. Esta visión también involucra el estudio de la práctica de violencia y no está limitada a sus actos intencionales, con motivos y objetivos más precisos, o para incidentes aparentemente espontáneos o aislados que interrumpen la regularidad de la vida diaria. La violencia aparece como una forma natural, pero drámatica, de cómo los individuos nos interrelacionamos y organizamos en la sociedad.

La violencia es una parte intrínseca del orden social, una realidad que engloba tanto los aspectos individuales y colectivos de la vida diaria. La violencia puede ser también una fuerza que desafía y destruye un orden social dado. Las prácticas sociales se ven como formas de resistencia, emergen tanto de individuos como de comunidades.

En la era de la posguerra fría, con el advenimiento de reformas neoliberales, se volvió más difícil pensar en la violencia dentro de la tradicional separación entre el Estado y las instituciones hegemónicas. La violencia se generalizó, manifestándose como una amenaza 
constante y creando una realidad en que cualquier persona puede ser víctima y victimario. Las ciudades se convirtieron en el principal escenario de la violencia, y el miedo como su característica definitiva.

Los medios para entender la violencia también han cambiado. La proliferación y la omnipresencia de las amanezas y la agresión han llevado a una crisis de significados, y las narrativas tradicionales parecen insuficientes para abarcar esta ubicuidad. Los análisis de la violencia se presentan cada vez más a través de las experiencias individuales y representaciones subjetivas, y son las fuentes principales para académicos, intelectules, artistas y periodistas para acercarse al fenómeno de la violencia.

Las ciudades, que anteriormente se estructuraban por la fluidez y el intercambio, se hacen cada vez más segregadas, a medida que sus habitantes han construido barreras en búsqueda de más seguridad. Las narrativas que emergen con respecto a la criminalidad se entrelazan con las nuevas transformaciones urbanas, creando nuevas prácticas y estructuras de significado. Nuevas categorías emergen, como la asociación entre violencia y marginalidad, que legitima comportamientos y percepciones que refuerzan el panóramo de temor.

Tales situaciones, unidas a la proliferación de un Estado cada vez más débil, dan mayor legitimidad a aquellos que buscan protección particular o justicia individual. Esto ha llevado a una diversificación no solo de las modalidades de la agresión, amenazas y miedo, también en las formas personales de la defensa. La distinción entre violencia legítima e ilegítima, opresión y resistencia, victimas y victimarios se hace cada vez más borrosas en el contexto.

La crítica contemporánea sobre la violencia urbana radica en los discursos hegemónicos que ayudaron a desarrollar este escenario de violencia, que asociaron la pobreza con la criminalidad. Al presentar la pobreza como una amenza a la sociedad, estos discursos implícitamente cultivaban el miedo y el deseo de protección superior. Detrás de los pretextos de estos discursos, los niveles de pobreza y exclusión social se agrandaron, haciendo de la desigualdad económica la forma principal de violencia de la región.

La desigualdad y las diversas formas de agresión, sin embargo, deben entenderse dentro de las historias locales específicas: contexto de guerra y posguerra, dictaduras y posdictaduras, el poder del narcotráfico y su violenta maquinaria, migración masiva y la experiencia de los migrantes.

La transformación de la violencia también establece relaciones y conexiones con el pasado. Si bien, el escenario actual es heterogéneo y más complejo que la violencia política de las décadas pasadas, los antiguas paradigmas persisten, en ocasiones por medio de las mismas personalidades e instituciones, en otras bajo una nueva imagen. Sin embargo, las ideas subyacentes tienen continuidad.

\section{Obras}

Se han seleccionado tres obras: “Los pájaros de Belén” (2000) de Serapio Umanzor y Mario Berríos, la columna "Grandes crímenes" (2008-) de Carmilla Wyler y la novela gráfica “Tranformar números en barcos piratas” (2017) de Germán Andino. Se hará una breve reseña de cada obra para luego realizar conclusiones generales sobre su papel en la representación de la violencia en las primeras décadas del XXI en Honduras. No se hará una valoración estético- 
literaria, en cambio, se tratarán de identificar sus valores culturales, lo particular de su medio y su efecto comunicativo.

\section{1 “Los pájaros de Belén” (2000) de Serapio Umanzor y Mario Berríos}

“Los pájaros de Belén” (2000) de Serapio Umanzor y Mario Berríos es una crónica de corte policial sobre la captura de la banda criminal de los "Bustillo Padillo", quienes fueron los raptores y asesinos de Ricardo Maduro Andrews, hijo del ahora expresidente Ricardo Maduro Joest, en el año 1997. La obra es una colaboración entre el periodista Serapio Umanzar y el capitán Mario Berríos, sin embargo, es Berríos quien continúa con una carrera liteararia con más de una docena de obras posteriores. Podemos atribuir a Umanzor el estilo periodístico con el que se escribió la crónica, ese mismo estilo es el que Berríos utilizará en sus obras posteriores para desarrollar ficciones a veces basadas en hechos reales.

Una búsqueda de crítica o análisis sobre la obra revela poco interés por parte de la academia por su estudio. Sin embargo, a no menos de seis ediciones, completamente agotadas a la fecha en Tegucigalpa, podemos catalogarlo como un superventas o "bestseller" local. El éxito comercial de la obra a inicio del siglo evidencia la necesidad del mercado en conocer los detalles y el funcionamiento de las nuevas bandas del crimen organizado, su operación y los esfuerzos que hace el Estado para su detención.

Umanzor, en la introducción del libro, coloca sus raíces en la novela policial del siglo XX, mencionando puntualmente el libro "A sangre fría" de Truman Capote. Aunque su corte es policial, no se evidencia la novela negra (noir) que caracterizó el género el siglo pasado. En la novela negra se difuminan los valores morales, surgen los héroes problemáticos, desarrollándose en contextos plagados de corrupción y disipación. Por el contrario, la crónica resalta la integridad moral del equipo policial ("Los Pájaros”), los sacrificios y la entrega completa al cumplimiento de tarea. Mario Berríos es el protagonista y sus hazañas son relatadas por Umanzor.

Además de poseer un corte policial, el libro también se apropia del género más inesperado: la novela testimonio o testimonial. El carácter híbrido del libro: no enteramente ficción, sino el testimonio de su protagonista, aunado la crónica periodística nos permite atribuirle este antecedente.

Es este trastoque del género testimonial que llama poderosamente la atención. El género fue utilizado en la década del 70 y 80 como el género por excelencia de los marginados y oprimidos, quizá el caso más conocido es el de "Me llamo Rigoberta Menchú y así me nació la conciencia" (1982-1983) de Rigoberta Menchú, con Elisabeth Burgos. Sin embargo, ahora en el 2000, son las fuerzas de seguridad del Estado quienes lo utilizan para describir un nuevo escenario de violencia.

Berríos no utiliza la obra como un panfleto político, y trata el desarrollo de la trama se aleja de las posturas políticas (derecha/izquierda), sin embargo, se identifican comentarios como la falta de apoyo económico de las fuerzas de seguridad, el debilitamiento que los gobiernos, específicamente el del Dr. Carlos Roberto Reina, habían causado, y no deja de mencionar que uno de integrantes de la pandilla, Efraín Ordóñez (alias Don Lentes), tuvo conexiones con el movimiento revolucionario "Cinchonero". Es decir, aunque el libro en una realidad “pospolítica”, el pensamiento de Berríos está atado a los paradigmas de los 80. 
De la misma forma en que los protagonistas de la novela testimonial se sentían reprimidos por un órgano todopoderosos, representado por el Estado. Son ahora las mismas fuerzas de seguridad que utilizan el género para expresar su impotencia ante una ola de violencia que parece superar las capacidades estructurales del Estado.

\section{2 “Grandes crímenes” (2008-) de Carmilla Wyler}

Los nuevos vehículos literarios también incluyen la columnas y suplementos semanales en diarios del país. El caso de Carmilla Wyler, quien tiene un suplemento dominical llamado “Grandes crímenes” en el diario El Heraldo de Tegucigalpa, es otro caso donde el género policial sirve como vehículo para la representación de la violencia en el país.

La columna es escrita bajo el seudónimo Carmilla Wyler, por ello conocemos poco del autor, aunque podemos deducir que tuvo experiencia dentro de alguna institución vinculada con la aplicación de justicia en el país, probablemente la policía.

El suplemento aborda un caso reconocido por semana, pueden ser casos emblemáticos, históricos, incluso descocidos. Utiliza técnicas propiamente de la ficción para narrar sus sucesos: escenas, diálogos, personajes, etc. No se limita a una crónica, reportaje o recuento de hechos. Trata de crear narraciones en donde conocemos las interioridades del proceso, desde el ilícito hasta su condena, y las repercusiones de sus familiares u otros implicados.

Wyler también saca partido de las mismas necesidades sociales que Berríos. Hay una necesidad cultural de conocer el accionar de las fuerzas de seguridad. Wyler se centra en la novela policial, específicamente el procedural (o procedimental), en donde conocemos paso a paso la resolución de un caso.

A diferencia de Berríos, Wyler se sale de la narrativa y no participa de los casos. Utiliza técnicas de ficción tradicional a través del periódico. Como lo menciona Héctor Leyva (2015) en su ensayo El discreto encanto del cuerpo social corrupto: violencia, literatura y medios de comunicación: "El éxito mediático pudo ser algo no buscado o inesperado para el autor", sin embargo, el hecho es que estamos ante otro fenómeno cultural masivo y popular que puede formar conciencia del fenómeno de la violencia de formas más efectivas que una novela tradicional.

El aporte de Wyler surge de cómo procesa el fracaso de las fuerzas de seguridad en la impartición de justicia. Wyler admite las debilidades del sistema, y aunque escribe claramente desde la perspectiva policial, no idealiza ni moraliza a sus miembros. Los agentes pueden ser corruptos, los abogados incompetentes y los jueces inoperantes. Sin duda esta es una representación más fiel del contexto nacional con respecto a Berríos.

Pero donde las fuerzas del Estado fracasan, surgen soluciones peligrosas. Debido a la flexibilidad de la ficción, Wyler puede buscar finales con mayor satisfacción fuera de los organismos legítimos. En varias de las historias aparece después de casos que no se resuelven por la vía legal, la figura del digitalismo y la justicia personal o particular.

Como lo menciona Leyva (2015):

En estos casos las cargas emotivas son autoritarias y antidemocráticas, no solo contrarias a las instituciones y al Estado de derecho sino exasperadas por ellos y lanzadas más allá 
de sus confines hacia el castigo paralegal: hacia el acto que desconoce el orden jurídico e institucional y hace justicia a su voluntad por su propia mano.

La privatización de la violencia también implica la privatización de la seguridad. Políticamente Wyler sigue la línea del fortalecimiento de las fuerzas de orden, sin embargo, admite la inexistencia de un monopolio de fuerza por parte del Estado y los vacíos que se crean y como se pueden resolver.

\section{3 “Transformar números en barcos piratas” (2017) de Germán Andino}

La novela gráfica web de Germán Andino ha sido merecedora de mucho reconocimiento crítico, incluso ha recibido el Premio Periodístico a la Investigación: Escribir sin Miedo por parte de PEN Canadá y el Premio Gabriel García Márquez a la Innovación por parte La Fundación para el Nuevo Periodismo Iberoamericano (FNPI). En este sentido la obra de Andino ha encontrado aceptación de la crítica, sin embargo, se desarrolla utilizando el lenguaje del cómic para representar la violencia.

El cómic nos cuenta la historia de Isaac, un tatuador y unos de los primeros pandilleros en Honduras, que se dedica cubrir los tatuajes de maras con la imagen de un barco pirata. Nos cuenta su vida, su difícil infancia y el contexto en donde surgen las maras y como estas organizaciones son un refugio para la juventud en riesgo social.

Andino es diametralmente opuesto a Berríos y Wyler, en lugar de buscar la solución de la violencia, se preocupa por sus orígenes. En lugar de ver la violencia como un agente externo, cuestiona las estructuras que la producen.

El cómic no ha sido un género muy cultivado o discutido en el medio, sin embargo utiliza un medio muy interesante: el internet. Este comic está diseñado en un sitio web del diario español El País, puede accederse únicamente por internet. El uso de nuevos medios, en este caso el digital, para la creación de espacios para la representación de la violencia es de vital importancia para resolver los grandes desafíos futuros.

Hasta ahora ninguno de los autores discutidos pudo estructurar una estética o medio por el cual abordar el carácter transnacional de la violencia actual. El narcotráfico y las pandillas son fenómenos trasnacionales, la obra de Andino abre la discusión para una experiencia compartida entre otros países que compartan la misma experiencia y los mismos desafíos.

\section{El mito pospolítico}

La representación de la violencia en las obras paraliterarias discutidas giran en torno a dos paradigmas: a) la violencia como un agente externo que irrumpe, y b) la violencia como producto de las estructuras del orden social vigente. En Berríos y Wyler, su identificación con las fuerzas del orden público para condicionarlos (predisponerlos) a no tratar de entender la violencia: únicamente resolverla, se adscriben al primer paradigma. Impera mencionar que entre Berríos y Wyler hay diferencias sustanciales, y si bien están próximos al mismo paradigma, se aproximan a él de distintas formas. En el caso de Andino, vemos su esfuerzo por relatar las condiciones que llevan un joven a la mara: los condicionantes y agravantes, su finalidad es comprender el fenómeno, sin duda está más cercano al segundo paradigma. 
Todas las obras fueron creadas dentro de una nueva realidad de la violencia en la región, en donde el motor es la narcoeconomía, los carteles y bandas son lo que administran el poder, y Estado debe compartir el poder con la delincuencia. Es decir, se encuentran dentro de un mal llamado entorno "pospolítico". Con ellos nos referimos a que las fuerzas políticas: izquierda versus derecha, han sido sustituidos por un contexto para complejo y heterogéneo.

Sin embargo, el éxito de la obra de Berríos y Wyler resalta que los mismos actores de los setentas y ochentas, existen aún y que su transformación pospolítica ha sido únicamente superficial. La vieja ideología castrense, conservadora y anticomunista se encuentra en sustrato de estas narraciones y sus narradores. Huelga decir que esta ideología es anacrónica, no obstante, subsiste oculta y silenciosa, buscando fuerzas políticas que la validen y las permitan expresarse. El golpe de estado de Honduras de 2009 es un ejemplo aislado en donde el fervor anticomunista (apuntado hacia el Socialismo de siglo XXI) encontró una forma de expresión política, aún y cuando no existía comunismo a que oponerse.

Otro ejemplo, más constante y vigente son las políticas de la "mano dura”, que siempre han tenido éxito en las urnas electorales. Una vez más, las obras Berríos y Wyler resaltan la necesidad de fuerzas policiales más efectivas para erradicar la violencia, no hay una reflexión profunda sobre las estructuras que las generaron. En Centroamérica, han sido las antiguas figuras de las dictaduras militares quienes han promovido la política de la "mano dura": el aumento del presupuesto militar, el recrudecimiento de condenas, etc.

Por otro lado, una obra como el cómic de Andino no ofrece (ni se propone ofrecer) soluciones a corto o mediano plazo, entender el fenómeno no implica resolverlo. Ya que el paradigma que lo sostiene, entiende a la violencia como el producto de un proceso orgánico-social. Sin embargo, son estas obras las que nos permitirán la creación de una identidad nacional frente a la violencia. No cabe duda que Andino es un caso excepcional y que su obra pasará a espacios más "legímitos" (cultura alta), sin embargo ha inaugurado un espacio para la creación gráfica, que esperamos sea utilizado por una nueva generación de creadores y consumidores de historietas.

\section{Conclusión}

El estudio de obras ubicadas en los márgenes de la academia nos ofrece una visión alternativa de la representación de la violencia. La obra literaria tradicional se preocupa esencialmente por las formas y su construcción estética. Si bien es cierto, es a través de estas creaciones estéticas en donde una verdadera propuesta puede surgir para representar nuesta violencia. Esto no resta importancia al trabajo de las obras paraliterarias como canalizador y reproductor del sentido popular. Entender estas manifestaciones, nos aproxima a entender el sentido popular de la violencia, y con ello poder ofrecer alternativas de reflexión y discusión, ya que estas representaciones generan un ciclo de creación y fortalecimiento de ideas con el público masivo.

La persistencia de ideas políticas obsoletas como sustento de las narraciones contemporáneas exige una contrapropuesta de la crítica, la academia y, sobre todo, los creadores. Debemos buscar nuevas formas estéticas para representar un entorno, pero sobre todo poseer ideas olíticas actuales para darla significado y significación al periodo de violencia que actualmente vivimos. 


\section{Referencias bibliografíca}

Andino, G. (2017, septiembre 29). El País. Retrieved from "Tranformar números en barcos piratas": https://elpais.com/especiales/2016/el-habito-de-la-mordaza/

Berríos, M., \& Umanzor, S. (2008). Los pájaros de Belén. San Pedro Sula: Pacura Editores.

Dorfman, A. (1970). La violencia en la novel hispanoamericana actual. In A. Dorfman, Imaginación y violencia en América (pp. 9-42). Barcelon: Anagrama.

Dueñas, G. P., \& Rueda, M. H. (2011). Meanings of Violence in Contemporary Latin America. New York: Palgrave MacMillan Press.

Leyva, H. (2015). El discreto encanto del cuerpo social corrupto: violencia, literatura y medios de comunicación. Itsmo, 1-22.

Mackenbach, W., \& Maihold, G. (2015). La transformación de la violencia en América Latina, un debate interdisciplinario. (pp. 1-16). Guatemala: F\&G Editores.

Maihold, G. (2015). La comunicación de la violencia: narcocorridos, narcomantas y narcosantos. (pp. 181-231). Guatemala: F\&G Editores.

Michael, J. (2015). Narco-violencia y redención en la literatura mexicana. (pp. 261-291). Guatemala: F\&G Editores.

Sidoli, O. C. (2004). Los daños punitivos y el derecho ambiental. elDial.

Zinecker, H. (2017). How to Explain and How Not to Explain Contemporary Criminal Violence in Central America. In: Politics and History of Violence and Crime in Central America. New York: Palgrave Macmillan. 